\title{
MESHYHA OCBITA
}

\section{DOI: $10.21802 / \mathrm{acm} .2021 .2 .3$ \\ REGULARITIES AND PRINCIPLES OF TRAINING THE STUDENTS FOR FUTURE PROFESSIONAL ACTIVITIES}

\author{
Skrobach NV, Shapoval OA, Vyshyvanyuk VYu, Petryna VO. \\ Department of Internal Medicine \#1, \\ Clinical Immunology and Allergology named after Academician Ye.M. Neyko \\ Ivano-Frankivsk National Medical University \\ Ivano-Frankivsk, Ukraine
}

\begin{abstract}
One of the most important results of the process of training students for future professional activity is the desired level of formation of their professional thinking. Thinking is a rational level and a way of forming cognitive, evaluative and practical actions. The peculiarity of this method is in the orientation of the subject to the objectivity, universality and productivity.

The approach to the concept of professional thinking as a special type of spiritual activity leads the researcher to work out the principle of monism of existence and thinking, and thus allows the derivation of forms of human spiritual activity from the laws of the material world, social practice, labor, social relations.

Training is performed on the basis of objective laws, according to which the class managers and those who study coordinate their actions. Education is a process of contradictory unity of reproductive and productive educationalcognitive activities of students.

Due to the fact that education involves the development of participants, it covers learning situations in which students study to master and manage the ways of professional productive activity.

Education - is a process of transition of a degree of educational-cognitive independence of participants of the classes into the quality of their material mastering.

This regularity draws attention to the existence of a connection between the educational-cognitive independence of the lessons participants and the quality of their material mastering. If the teacher evaluates only the results of the students' actions as such, ignoring the fact that the class participant has no knowledge, skills, thus - he is wrong. The students must be given the opportunity to make up lost ground, enrich their fund with the new experience, inspire confidence in success.

The subject distinctness of the professional thinking is that the subject of work (occupation, business) "dictates" the way it is understood, i.e., knowledge of the material becomes a form of thinking. When studying the impact of technology on the human consciousness, we should not only talk about the coincidence of the forms of objects with the forms of thinking, but definitely highlight the unity of professional actions and the logic of professional thinking.
\end{abstract}

Key words: principles of training, students, professional activity, study outcomes, thinking.

One of the most important results of the process of teaching students for future professional activity is the desired level of formation of their professional thinking [7]. Thinking - is a rational level and a way of forming cognitive, evaluative and practical actions. The peculiarity of this method is in the orientation of the subject to the objectivity, universality and productivity [4].

Professional thinking as a type of spiritual activity is characterized, first of all, by the fact that work, occupation, business are the main determinant factors which connects, "filters", transforms the influence of all other social factors [1].

As usual, experts divide the consciousness into cognition, emotions and will, pointing to two levels (feeling and thinking) only in cognition. As a result, thinking is interpreted only as a cognitive activity [6].

Training is performed on the basis of objective regularities, according to which the class managers and those who study coordinate their actions. Learning is a process of contradictory unity of reproductive and productive educational-cognitive activities of students [2].

Those who study, understand and master new learning material, be sure to reproduce it in situations of consolidation and application of knowledge, skills and abilities [5]. Therefore, training always involves the assimilation and reproduction of material. Training must take into account the experience gained, knowledge, abilities of students [3].

Since education involves the development of lessons participants, it covers such learning situations in which students study to learn and master the ways of professional productive activity [7].

Learning - is a process of transition of a degree of educational-cognitive independence of participants of classes into the quality of their training material mastering. 
Learning - is the unity of functioning, productive activity and new functioning, in which new educational content is synthesized.

The main regulations according to which training is built - are the principles of training. The system of principles of teaching relies on its regularities. They are the most important generalized means of organizing and managing the learning process. The principles are arranged in a certain sequence. They are internally interconnected and mutually conditioned [7].

1. The principle of conformity of socialpsychological and individual-psychological peculiarities of lessons participants to the specificity of training. It points to the necessity to adapt participants to the learning system - self-awareness of them as the students, willingness to learn, to perform students' functions. The head of classes applying this principle must take into account the career of students, their age, gender, previous education, in some situations - marital status, as well as peculiarities of perception, attention, thinking, imagination, will, temperament, character, abilities, etc. At the same time, it is necessary to take into account experience and general professional development, to take it into account in relation to the specificity of training, but not in general.

2. The principle of conscious educational-cognitive activity of participants in training. The teacher violates this principle when he does not create conditions for the participants to identify their activities, initiatives, tries to present the educational material in the "ready form", requires a mechanical repetition of his/her actions, etc. According to the requirements of this principle, the class teacher must provide favourable conditions for the pedagogical direction of students' activity and independence. The process of learning and mastering the techniques of professional activity should be conscious and active, outlined by a certain theoretical and practical independence.

3. The principle of conformity of qualities of lessons participants to specificity of training and conscious educational-cognitive activity, make internally interconnected parties of uniform process of training.

4. The principle of training scientificity indicates that the lesson supervisor must take into account the patterns of study, as well as the regularities contained in the educational material, in the psychology of perception, imagination, understanding of the studied material. The principle of scientificity obliges the teacher to improve teaching methods based on the latest scientific advances.

In accordance with the requirements of the principle of scientific training, the class manager builds pattern achievable for the existing contingent, preplans, designs, implements situations of difficulties and mistakes as a means of professional-cognitive development and education.
5. The principle of clarity and use of visual methods in study. Student's education includes a wide range of forms of study. Subject visualization in the form of tools; verbal-figurative clarity in the descriptions of professionally significant events in the life of prominent figures of the industry, society, humanity; conditionalpictorial clarity - diagrams, pictures, tables, etc.; dynamic clarity - movies, television, VCR.

This principle is implemented at all stages of training, because it determines the effective working out of professional tools, methods of operation by means of analysis, synthesis, interpretation, evaluation, including assessment of their own work, previously filmed.

6. The principle of regularity and consistency of education. Students are taught according to a certain scheme - the study material is represented in a logical sequence, based on the available experience, knowledge, ideas, skills and abilities.

The requirements of regularity of study oblige the teacher to build the process according to didactic logic. It determines the sequence and nature of elaboration of themes and tasks, study of the material in its gradual complication. At the same time, this principle obliges the teacher to be guided by the logic inherent in the professional peculiarities of the studied case. This means that the head of classes, considering the system and sequence of distribution of training stages, follows the logic of professional work, which appears as a training material.

7. The principle of problematicity of education. Compliance with the requirements of this principle demands from the supervisor to design new teaching aids. It is important to master new techniques in capturing the means of solving professional problems. Therefore, during the lessons it is important for the leader to throw the participants into the different situations of creative search and discovery of new ways to solve professional problems. As educational material the selected professional processes are reproduced and based on it some educational-problematic situations on the foundation of which it is possible to consider life facts and circumstances, are organized. According to the principle of problem-based learning, the teacher is obliged to create conditions for professional-creative activities.

Professional-research activity of lesson participants - is the most troublesome and difficult form of educational work. Participants learn to look for the correct solution, to argue and defend their own point of view, to see the shortcomings in their own actions and the actions of their colleagues; each time to find some new approach to the educational-problematic situation, and if necessary, to abandon the event, finding it wrong. Individual acquiring new knowledge as well as working on generalizations and conclusions - is an 
effective way of actively and consciously mastering future responsibilities.

8. The principle of collective study. At the request of this principle of learning, the group, unit, team is educated as a whole. Conditions are created for purposeful coordinated work of all links. Training is consistent with the basic mechanisms of team development. Educational work, along with tutorial work, is coordinated with future production activities, is built in accordance with the immediate, middle and future prospects - this is the unity of reproductive and productive activities. Participants of the educational unit must be aware of the goals of the created team, contribute to its success, fight for self-affirmation of its authority in the university. The head of classes always faces the problem of organic combination of generalcollective and small-group activities, favourable planning and appropriate use of their interaction, variable involvement of participants into various forms of professional-creative work, accustoming students to actions from the position of "leader", as long as there is always the necessity to help someone in the team.

The collective nature of study contributes to the acquisition of the ability to learn, take into account the views of other team members, coordinate one's actions with others, seek and find common solutions.

9. The principle of individualization of study. This principle draws the teacher's attention to taking into account not only the individual characteristics of the participants as such, but mainly to the pedagogically purposeful individualization of education. In accordance with the requirements of this principle, whatever form of organization of training is resorted to during the classes - whether collective, group or individual - finally the most important thing is to form the professional-creative personal and individual qualities of students.

10. The principle of professional interest in study. This principle is based on the specificity of the professional future activities of students. Participants of the lessons love to discuss professionally significant issues during their studies and in their free time. Therefore, study should be performed in an atmosphere of friendliness and joy of discovery. To do this, the teacher should make some efforts to create an appropriate psychological climate of professional-creative search. Students' enthusiasm for future professional work is inevitably associated with moral-ethical requirements for the personality, without which it is impossible to successfully carry out training and education.

The principle of professional interest in study reveals the necessity to create an atmosphere of joyful discovery of professional secrets, which enriches the inner world of participants with vivid impressions of the future profession and communication with friends, supervisor while mastering the tools and techniques of future professional work.

11. The principle of conjunction of study with practical activities in the professional future. This principle reflects the connection between the student's learning and the specificity of future professional activity. It acquires its expression in the choice of educational material. It focuses on information about the current state, development, direction and purpose of the relevant organizations and the relevant industry. The learning process is planned and carried out by the facilitator according to the future professional process and the future responsibilities of the students. Education is necessarily associated with the students' accustoming to perform those professional operations that will soon be performed by lessons' participants.

12. The list of principles would be incomplete without the final principle - the principle of strength of learning outcomes. This principle draws attention to the necessity for strong mastering of the content of educational material, means and methods of activity, and thus allows you to check the success of the application of the above-mentioned principles. After all, in the case when future specialists have firmly mastered the selected links of the technological process, which was being studied, but roughly imagine other links in the technological chain, the requirements of the principle of strength of the study outcomes are not fully met. It should be emphasized that the principle of strength of the study outcomes reveals the true effectiveness of learning only when it is applied to those aspects of education that come from the content of all the abovementioned principles. Therefore, it is important that participants of the lessons could not only memorize and correctly reproduce practical actions, but on this basis could demonstrate the creative nature of understanding and performing professional operations along the entire technological chain provided by the curriculum.

The objective distinctness of professional thinking is in the fact, that the subject of labor (occupation, business) "dictates" the way of understanding it, that is, knowledge of the material becomes a form of thinking. When studying the influence of technologies on human consciousness, we should not only talk about the coincidence of the forms of objects with the forms of thinking, but also be sure to highlight the unity of professional actions and the logic of professional thinking.

Conflict of Interest. The authors declare that no conflicts exist.

Financial Disclosure. The authors declared no financial support.

\section{References}

1. Baranova IV, Iliuk IA, Postovitenko KP. Motivation 
to study as the key to the effectiveness of modern medical education. Medychna osvita. 2019;2:55-60. Available from: https://doi.org/10.11603/me.2414-5998.2019.2.10344

2. Dereziuk AV. Some aspects of modern pedagogy of medical education. Medychna osvita. 2015; 3: 26-28.

3. Kondratiuk VY, Shevchuk SG, Khomaziuk VA et al. Competence approach to teaching propaedeutics of internal medicine. Medychna osvita. 2019; 1: 79-81. Available from: https://doi.org/10.11603/me.2414-5998.2019.1.10087

4. Lavrovska AA, Lapinska TV. Interdisciplinary and integrated connections as a necessary component in the study of clinical subjects. Magistr medsestrynstva. 2018; 1(19): 41-44.

5. Pavliak AY. Experience of conducting practical classes using interactive methods of forming professional skills of future medical workers. Experience of conducting practical classes using interactive methods of forming professional skills of future medical workers. Medychna osvita. 2019; 1: 102-106.

6. Rakitianska L. The essence and meaning of the concept of "emotional intelligence". Pedagogichnyi process: theory and practice. $2018 ; 4: 35-42$. Available from: https://doi.org/10.28925/2078-1687.2018.4.3542

7. Vykhrushch AV, Elagina NI, Klishch GI. The quality of university education: current issues of theory and practice: a collective monograph. Edited by Vykhrushch AV. - Ternopil: TNEU: 2016; 525p

Received: 23.11.2021

Revised: 29.11.2021

Accepted: 29.11.2021 